\title{
The Response of Corneal Endothelial Cells to Shear Stress in an In Vitro Flow Model
}

\author{
Sujuan Duan $\mathbb{D}^{1,2}$ Yingjie Li ${ }^{1},{ }^{1}$ Yanyan Zhang $\mathbb{D}^{,},{ }^{3}$ Xuan Zhu $\mathbb{D}^{1},{ }^{1}$ Yan Mei ${ }^{1},{ }^{1}$ \\ Dongmei $X u \mathbb{D}^{4}{ }^{4}$ and Guofu Huang $\mathbb{D}^{1,2}$ \\ ${ }^{1}$ Department of Ophthalmology, First Hospital of Nanchang, Nanchang, Jiangxi 330008, China \\ ${ }^{2}$ Jiangxi Key Laboratory of Cancer Metastasis and Precision Treatment, First Hospital of Nanchang, Nanchang, \\ Jiangxi 330008, China \\ ${ }^{3}$ Medical Department of Graduate School, Nanchang University, Nanchang, Jiangxi 330006, China \\ ${ }^{4}$ Department of Ophthalmology, Xingguo People's Hospital, Ganzhou, Jiangxi 342400, China
}

Correspondence should be addressed to Guofu Huang; huangguofu8673@dingtalk.com

Received 20 June 2021; Accepted 27 October 2021; Published 27 November 2021

Academic Editor: Van C. Lansingh

Copyright (c) 2021 Sujuan Duan et al. This is an open access article distributed under the Creative Commons Attribution License, which permits unrestricted use, distribution, and reproduction in any medium, provided the original work is properly cited.

\begin{abstract}
Purpose. Corneal endothelial cells are usually exposed to shear stress caused by the aqueous humour, which is similar to the exposure of vascular endothelial cells to shear stress caused by blood flow. However, the effect of fluid shear stress on corneal endothelial cells is still poorly understood. The purpose of this study was to explore whether the shear stress that results from the aqueous humour influences corneal endothelial cells. Methods. An in vitro model was established to generate fluid flow on cells, and the effect of fluid flow on corneal endothelial cells after exposure to two levels of shear stress for different durations was investigated. The mRNA and protein expression of corneal endothelium-related markers in rabbit corneal endothelial cells was evaluated by real-time PCR and western blotting. Results. The expression of the corneal endothelium-related markers ZO-1, $\mathrm{N}$-cadherin, and $\mathrm{Na}^{+}-\mathrm{K}^{+}$-ATPase in rabbit corneal endothelial cells (RCECs) was upregulated at both the mRNA and protein levels after exposure to shear stress. Conclusion. This study demonstrates that RCECs respond favourably to fluid shear stress, which may contribute to the maintenance of corneal endothelial cell function. Furthermore, this study also provides a theoretical foundation for further investigating the response of human corneal endothelial cells to the shear stress caused by the aqueous humour.
\end{abstract}

\section{Introduction}

Mechanical signals can regulate various cellular biological behaviours, such as cell proliferation, apoptosis, migration, differentiation, and shape reconstruction [1-6]. A variety of tissue cells, such as vascular endothelial cells [7-9], smooth muscle cells $[10,11]$, stem cells $[5,12,13]$, and leukocytes $[14,15]$, have been studied after exposure to mechanical stimuli. The importance of mechanical signals is particularly relevant to the cardiovascular system. Both corneal endothelial cells and vascular endothelial cells exist in similar fluid environments, but little is known about the effect of fluid on corneal endothelial cells.

The limited studies about the effects of fluid force on ocular tissues have shown that the shear stress generated by fluid flow can regulate cell morphology, gene expression, and signalling cascades. For example, Akihiro [16] demonstrated that shear stress regulated gene expression in human retinal microvascular endothelial cells. Ulrike et al. found that shear stress could change cellular morphology and affect cell junction protein expression [17]. High shear stress may disrupt the phenotype and barrier function of the blood barrier in the retina [18]. Fluid shear stress inhibited wound healing and may be associated with modulation of the TGF- $\beta$ signalling pathway in cultured corneal epithelial cells [19]. Application of axial strain in the physiological range to rabbit corneal fibroblasts downregulated $a$-SMA expression [20]. Corneal epithelial cells responded favourably to shear stress and exhibited morphological alterations, which affected their proliferation and migration behaviours, 
in response to two different magnitudes of shear stress [21]. We speculated that shear stress that results from the aqueous humour may also influence corneal endothelial cells. Yasuaki et al. also found that when human corneal endothelial cells were exposed to a fluid environment, the number of cells attached to the slide decreased as the magnitude and duration of the shear stress increased [22]. However, there are currently no reports on the gene expression of corneal endothelial cells after exposure to shear stress.

In studies of the effects of fluid shear stress on the ocular surface, the main focus has been on the effects of fluid flow caused by blinking on the corneal epithelium. Only a few studies reported the magnitude of fluid shear stress to which the corneal endothelium is exposed $[22,23]$. In fact, the exact magnitude of the shear stress to which corneal endothelial cells are exposed under physiological conditions in vivo is still unknown. Yasuaki calculated the magnitude of the shear stress to which corneal endothelial cells are exposed due to the aqueous humour using three-dimensional anterior chamber models and the magnitude of shear stress used by Yasuaki ranged from 0 to $0.58 \mathrm{dyn} / \mathrm{cm}[2,22]$. Yuichi proposed the porcine endothelial cells were exposed to shear stresses $\left(0.1-10 \mathrm{dyn} / \mathrm{cm}^{2}\right)$ for 15 minutes for the experimental conditions [23]. As reference materials, we investigated the response of RCECs to two levels of shear stress $\left(0.5 \mathrm{dyn} / \mathrm{cm}^{2}\right.$ and $\left.2 \mathrm{dyn} / \mathrm{cm}^{2}\right)$. In preliminary experiments, we compared the effects of exposure to $0.5 \mathrm{dyn} / \mathrm{cm}^{2}$ and $1 \mathrm{dyn} / \mathrm{cm}$ [2], and the there is no significant difference of genes expression (data not shown). Another reason is that we cannot generate shear stresses below $0.5 \mathrm{dyn} / \mathrm{cm}^{2}$ because of the limitations of the peristaltic pump. In the present study, we chose two levels of shear stress $\left(0.5 \mathrm{dyn} / \mathrm{cm}^{2}\right.$ and $2 \mathrm{dyn} / \mathrm{cm}^{2}$ ) to investigate the effect of fluid flow on RCECs. A complete parallel plate flow chamber system was established to generate fluid shear stress. Then, the following conditions were chosen: (1) $0.5 \mathrm{dyn} / \mathrm{cm}^{2}$ shear stress for $30 \mathrm{~min}$ or $2 \mathrm{~h}$, (2) $2 \mathrm{dyn} / \mathrm{cm}^{2}$ shear stress for $30 \mathrm{~min}$ or $2 \mathrm{~h}$, and (3) no shear stress (control group). We analysed responses of RCECs to shear stress, including changes in gene and protein expression.

\section{Materials and Methods}

2.1. Animals. Healthy New Zealand white rabbits weighing 2.0-3.0 kilograms were used in the present study and were purchased from the Department of Experimental Animal Science of Nanchang University (Jiangxi, China). All the animals used in the study were handled according to the Association for Research in Vision and Ophthalmology (ARVO) statement.

2.2. Isolation and Culture of Cells. The RCECs were isolated using the previously described "peel-and-digest" method with some modifications [24]. Briefly, rabbit eyes were obtained with a sterile surgical apparatus after the rabbits had been sacrificed. Under a stereoscopic dissecting light microscope, the whole cornea was dissected from the limbal zone, and Descemet's membrane, containing the endothelium, was then peeled off. Next, Descemet's membrane was washed with PBS three times and incubated in a basal culture medium (DMEM; with 10\% foetal bovine serum and $1 \%$ penicillin-streptomycin) overnight at $37{ }^{\circ} \mathrm{C}$ in $5 \% \mathrm{CO}_{2}$. To isolate the primary corneal endothelial cells, the membrane was washed with PBS again and then digested with $0.5 \mathrm{~mL}$ of $0.25 \%$ ethylenediaminetetraacetic acid (EDTA) (Solarbio, Beijing, China) for 2 min at $37{ }^{\circ} \mathrm{C}$ in $5 \%$ $\mathrm{CO}_{2}$. Then, the EDTA was carefully removed, and the cells were suspended by flushing with the basal culture medium. Then, a suspension $\left(2 \times 10^{6}\right.$ cells per ml) was cultured in Corning $35 \mathrm{~mm}$ tissue culture dishes for the following experiments.

2.3. Shear Stress Experiments. A parallel plate flow chamber (Glycotech, Gaithersburg, MD, USA) was used to expose cell monolayers to laminar shear stress. One side of the flow chamber was the Corning $35 \mathrm{~mm}$ tissue culture dishes in which the RCECs were cultured, and the other side was the flow decks, which included three threaded holes to fit the inlet, outlet, and vacuum pump. These two flat surfaces were held apart by a round gasket. The flow chamber kit included a parallel plate flow chamber, a peristaltic pump (Baoding Longer Precision Pump Co., Ltd, China), a vacuum pump (Shanghai, China), and a medium reservoir. The vacuum pump tightly held the three components of the parallel plate flow chamber. These components were connected with several silicone tubes and connectors. Figure 1 shows a schematic of the experimental setup used in the study. The shear stress acting on the cells was estimated using the following equation: $\mathrm{TT}=6 \mu \mathrm{Q} / \mathrm{a}^{2} \mathrm{~b}$, where $\mathrm{T}$ is the shear stress in dyn/cm [2], $\mu$ is the apparent viscosity of the perfused fluid, $Q$ is the volumetric flow rate $(\mathrm{mL} / \mathrm{s})$, and a and $b$ are the channel height (i.e., gasket thickness) and width (i.e., gasket width) $[16,25]$. The shear stress was altered by changing the pump rotation velocity and volume flow. All the flow experiments were conducted in a standard incubator. Before applying shear stress to the RCECs, the Corning $35 \mathrm{~mm}$ tissue culture dishes were treated with $50 \mathrm{ug} / \mathrm{ml}$ fibronectin (BD, America) for $2 \mathrm{~h}$ in the incubator, and the same procedure was applied to the control group. Then, the fibronectin was removed, and $2 \times 10^{6}$ cells per $\mathrm{ml}$ were seeded in the Corning $35 \mathrm{~mm}$ tissue culture dishes and grown until the cells reached confluence. Then, the cells were used for subsequent fluid experiments. The cells in the experimental group were exposed to shear stress, and cells from the same rabbit seeded in fibronectin-coated Corning culture dishes but not exposed to shear stress were used as controls.

2.4. Real-Time PCR. Total RNA was extracted from RCECs with TRIzol reagent (Tiangen Biotech, Beijing, China) according to the manufacturer's instructions. The genomic DNA in the samples was then removed with DNase, and then, the total RNA concentration of each sample was measured by using Nanodrop 2000 (Thermo, ND-2000). cDNA was synthesized in a $20 \mu \mathrm{l}$ reaction system containing $1 \mu \mathrm{g}$ of RNA with a cDNA Synthesis Kit (Takara, Dalian, 


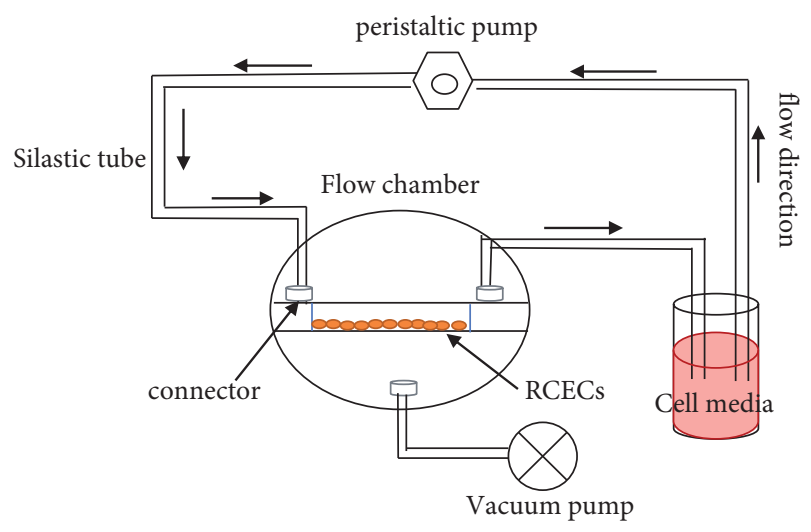

Figure 1: Diagram of the flow circuit system. The flow circuit included a parallel plate flow chamber, a peristaltic pump, a vacuum pump, and a medium reservoir, and these components were connected by silicone tubes and connectors.

China) according to the protocol. Then, real-time PCR was conducted in a $20 \mu \mathrm{l}$ reaction mix that included $10 \mu \mathrm{l}$ SYBR Green (Takara, Dalian, China), $0.5 \mu \mathrm{l}$ paired primers, $2 \mu \mathrm{l}$

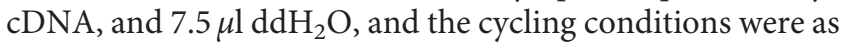
follows: $95^{\circ} \mathrm{C}$ for $20 \mathrm{~s}$ followed by 45 cycles of $94^{\circ} \mathrm{C}$ for $10 \mathrm{~s}$ and $58{ }^{\circ} \mathrm{C}$ for $35 \mathrm{~s}$. Relative gene expression was analysed using the comparative $\mathrm{Ct}(\Delta \Delta \mathrm{Ct})$ method. The primers used in real-time PCR are listed in Table 1.

2.5. Western Blotting. RCECs stimulated with or without shear stress were collected using a scarper and subsequently lysed with RIPA buffer containing protease inhibitors according to the manufacturer's protocol. The lysates were centrifuged, and the supernatants, which contained the total proteins, were then collected. Protein quantification was performed with a BCA Protein Assay Kit (Beyotime, Shanghai, China) according to the manufacturer's protocol. To denature the proteins, $20 \mu \mathrm{g}$ of proteins and $5 \mathrm{X}$ sodium dodecyl sulfate (SDS) were mixed together and boiled for 10 minutes. Then, the proteins were loaded onto a $10 \%$ sodium dodecyl sulfate-polyacrylamide gel electrophoresis (SDSPAGE) gel, separated by electrophoresis, and then transferred to a polyvinylidene fluoride (PVDF) membrane (Millipore Corp, Bedford, MA). Then, the membrane was blocked with $5 \%$ skim milk at room temperature for $2 \mathrm{~h}$, followed by incubation with the primary antibody at $4{ }^{\circ} \mathrm{C}$ overnight. Next, the membrane was incubated with the corresponding secondary antibody. The protein bands were detected using an enhanced chemiluminescent reagent (KeyGEN BioTECH, Nanjing, China), and the band densities were analysed by ImageJ.

2.6. Statistics. All the experiments in the study were repeated at least three times. All the values are represented as the mean \pm standard error. One-way ANOVA was used to compare the mean values, and the statistical significance of differences was determined using Bonferroni's post hoc test when a significant $\mathrm{F}$ ratio was observed. $P<0.05$ was considered statistically significant.

\section{Results}

3.1. The mRNA Expression of Corneal Endothelial Cell-Related Markers in Response to Shear Stress. The expression levels of corneal endothelial cell-related genes were evaluated under shear stress and static conditions. Figure 2 shows the altered mRNA expression of the corneal endothelial cell-related markers ZO-1, N-cadherin, and Na+-K+-ATPase in RCECs cultured under static and shear stress conditions. After the continuous exposure of RCECs to $0.5 \mathrm{dyn} / \mathrm{cm}^{2}$ for $0.5 \mathrm{~h}$ and $2 \mathrm{~h}, \mathrm{ZO}-1$ mRNA expression gradually increased with prolonged exposure time compared with that in the cells exposed to static control conditions $(1.55 \pm 0.276$ and $3.76 \pm 0.29$ vs. $1 \pm 0.32$ ). When the cells were exposed to shear stress up to $2 \mathrm{dyn} / \mathrm{cm}$ [2], the mRNA expression of ZO-1 was significantly upregulated $(11.6 \pm 0.23$ and $12.24 \pm 0.31$ vs. $1 \pm 0.32$ ) (Figure 2(a)). The mRNA levels of $\mathrm{N}$-cadherin showed a trend similar to that of ZO-1 mRNA expression after exposure to shear stress (Figure 2(b)). The mRNA expression of $\mathrm{Na}^{+}-\mathrm{K}^{+}$-ATPase was slightly increased under lower stress conditions. When shear stress reached $2 \mathrm{dyn} / \mathrm{cm}$ [2], the expression levels of $\mathrm{Na}^{+}-\mathrm{K}^{+}$-ATPase were significantly upregulated $(1.45 \pm 0.33$ and $1.52 \pm 0.38$ vs. $1 \pm 0.12$ ) (Figure 2(c)).

\subsection{Effects of Shear Stress on the Expression of Proteins Related} to Corneal Endothelial Cell Function. The protein levels of corneal endothelial cell-related markers were assessed in at least three independent experiments. ZO-1 protein expression was significantly increased under shear stress conditions compared to static conditions (Figure 3(a)). This effect did not seem to occur in a time- or force-dependent manner. The protein expression of both $\mathrm{N}$-cadherin and $\mathrm{Na}^{+}-\mathrm{K}^{+}$-ATPase gradually increased with increasing shear force and exposure time, which appeared to be consistent with the mRNA expression results described above (Figures 3(b) and 3(c)).

\section{Discussion}

Corneal endothelial cells (CECs) form a monolayer of hexagonal cells between Descemet's membrane (DM), and the aqueous humour serves as a barrier and a pump, thus playing a pivotal role in the maintenance of corneal transparency [26]. The aqueous humour, a fluid circulating in the eye, plays a crucial role in maintaining the homeostasis of corneal endothelial cells. Although the influence of flow on vascular endothelial cells has been well documented, fluid flow within corneal endothelial cells has been ignored. We, therefore, hypothesized that shear stress from the aqueous humour may also exert meaningful effects on corneal endothelial cells. The present study demonstrated, for the first time, that fluid shear stress affected the gene expression of corneal endothelial cell-related markers in cultured RCECs.

A major function of the corneal endothelium is to maintain corneal transparency by regulating corneal hydration, which is mediated by its barrier and pump function 
TABLe 1: The primers used for real-time PCR.

\begin{tabular}{llc}
\hline GENE & Forward Primer & Reverse Primer \\
\hline ZO-1 & AGTTTGGCAGCAAGAGATGG & GCTGTCAGAAAGGTCAGGGA \\
$\mathrm{Na}^{+} / \mathrm{K}^{+}$-ATPase & CGGCTACAAAGACGGCAAAC & GAACAGGCAGCACATTTGGG \\
$\mathrm{N}-\mathrm{cadherin}$ & ATGGCTTGGAATGAGACTGC & CCACCAGAGTGAAAGGAACG \\
GAPDH & GCACCGTCAAGGCTGAGAAC & TGGTGAAGACGCCAGTGGA \\
\hline
\end{tabular}

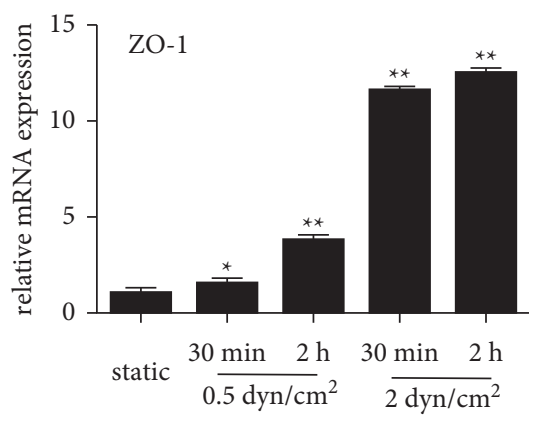

(a)

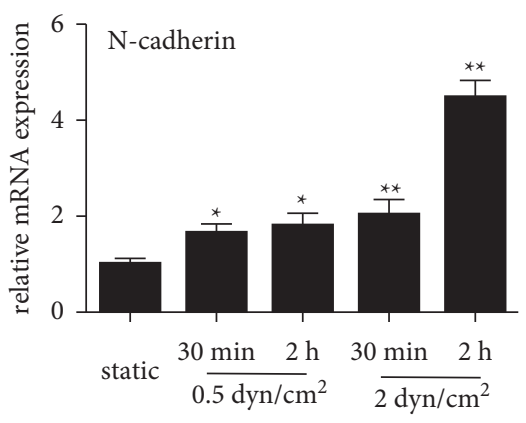

(b)

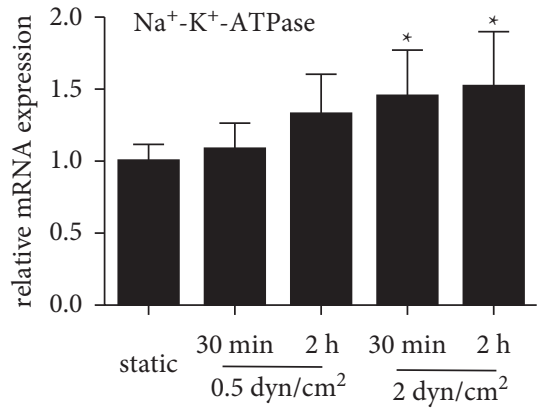

(c)

FIGURE 2: Effect of shear stress on the mRNA expression of corneal endothelial cell-related markers. (a) ZO-1 mRNA expression was significantly increased after treatment with shear stress $\left(0.5 \mathrm{dyn} / \mathrm{cm}^{2}\right.$ and $\left.2 \mathrm{dyn} / \mathrm{cm}^{2}\right)$ for $30 \mathrm{~min}$ and $2 \mathrm{~h}$. (b) N-cadherin mRNA expression gradually increased as the shear stress intensity increased compared with the static control. (c) $\mathrm{Na}^{+}-\mathrm{K}^{+}$-ATPase mRNA expression was slightly increased after exposure to shear stress. The data are presented as the mean $\pm \mathrm{SD} ;{ }^{*} P<0.05,{ }^{* *} P<0.01$.

$[27,28]$. ZO-1 is a tight junction protein, and $\mathrm{N}$-cadherin is an anchoring junction protein. Both proteins play key roles in barrier function and maintain the water content in the cornea at a suitable level [29-31]. $\mathrm{Na}^{+} / \mathrm{K}^{+}$-ATPase, a membrane transport protein located in the corneal endothelium, promotes the pump function of corneal endothelial cells by removing excess stromal fluid to maintain corneal transparency [32, 33]. Shear stress can be beneficial to maintain the function of different types of cells, depending on the magnitude and duration of the shear stress [34-36]. In the current study, corneal endothelial cells exhibited altered transcription levels and protein expression levels of marker genes in response to the application of shear stress (2 and 3). The mRNA levels of ZO-1 were significantly upregulated in the $2 \mathrm{dyn} / \mathrm{cm}^{2}$ group, whereas the protein expression levels were slightly altered in our study. The inconsistent results may be due to the influence of multiple factors, and mRNA changes do not necessarily always correlate with protein changes. Overall, shear stress induced the expression of corneal endothelial cell function-related markers, which is consistent with previous studies performed on vascular endothelial cells [37-39]. These results reveal that RCECs are sensitive to shear stress, which may be involved in the maintenance of corneal endothelial cell function.

This study had some limitations. First, we just observed the alterations of the cell morphology under the microscope with or without shear stress exposure. As shown in Supplementary Figure 1, there is no significant change in cell morphology after shear stress treatment. This is inconsistent with the research proposed by Akihiro and Nicole that the cells are aligned with the direction of the fluid after shear stress exposure $[16,40]$. We speculated that the reasons were related to the different cell types and short time of shear stress exposure. But, when we prolonged the RCEC exposure time, more cells started to detach from the culture dishes, even though we changed the perfusion medium, which is consistent with the literature reports [22, 23]. We also conducted ZO-1 staining analysis. However, it has encountered obstacles for us since RCECs exposed to shear stress are easier to get detached from the slides during the process of fixing and washing. We hope to obtain better results by optimizing the experimental conditions in the next experiments. Second, when applying the in vitro data to in vivo situations, some differences should be considered; for example, the attachment of the cells to culture slides or to Descemet membranes may not be the same. Our experimental device is a closed circuit that consists of only corneal endothelial cells and unidirectional laminar flow. This might explain why shear stress increased the expression of corneal endothelial cell-related genes. In fact, corneal endothelial cells are influenced by the shear stress of the aqueous humour, various growth factors in the aqueous humour, the biophysical microenvironment of Descemet's membrane, hydrostatic intraocular pressure, and the temperature of the cornea [41-44]. We cannot simulate the combined effects of these factors on corneal endothelial cells in the present study. Thus, we need to interpret the results of the current study with caution. Third, the mechanism by which increased expression of corneal endothelial cell-related markers was induced after shear stress has not been elucidated, but the mechanism may be related to the fluid activating-related intracellular signalling pathways and requires further investigation. Last, we did not replicate our results in human corneal endothelial cells. Although human corneal endothelial cells are more difficult to expand in vitro 


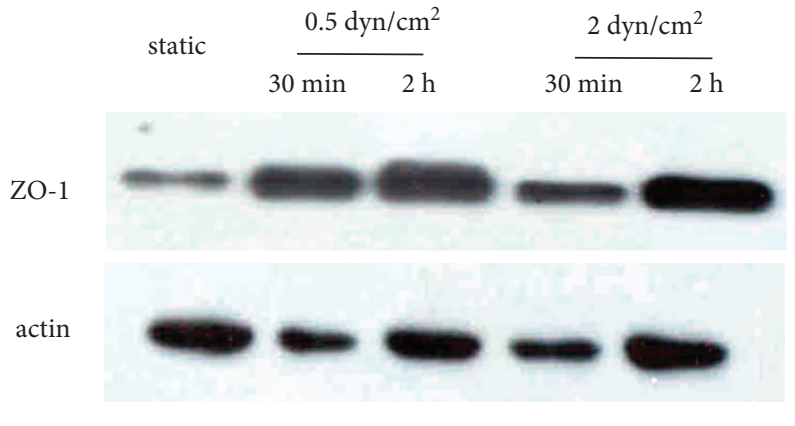

(a)

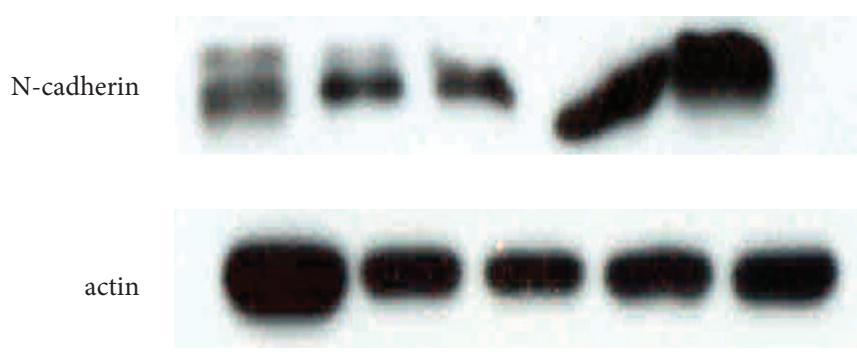

(b)

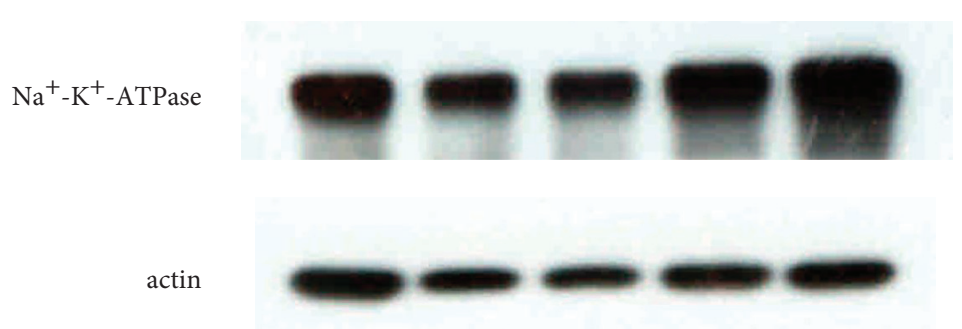

(c)
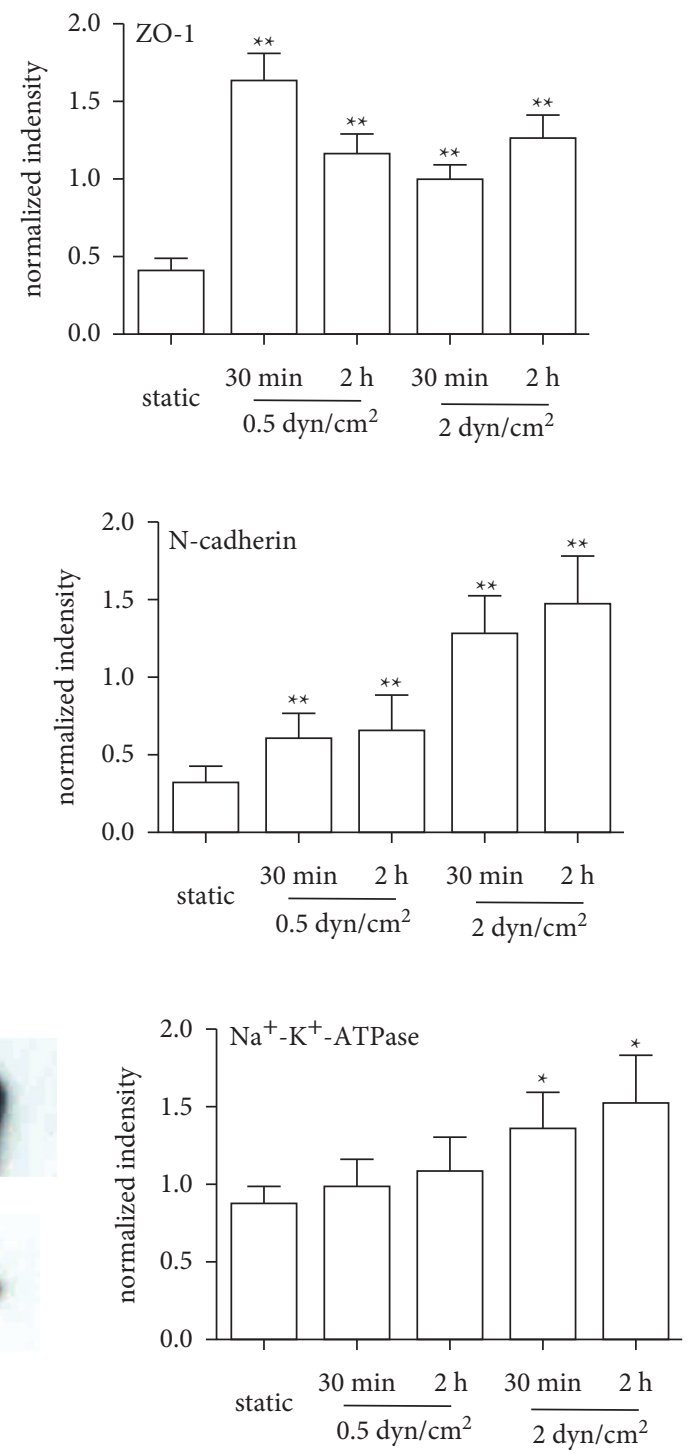

Figure 3: Effect of shear stress on the protein expression of corneal endothelial cell-related markers. (a) ZO-1 protein expression was significantly increased in the shear stress groups compared with the static group. (b) $\mathrm{N}$-cadherin protein expression gradually increased with increasing shear rates and exposure time. (c) $\mathrm{Na}^{+}-\mathrm{K}^{+}$-ATPase protein expression was slightly increased after exposure to shear stress. All the experimental data were analysed in triplicate; ${ }^{*} P<0.05,{ }^{* *} P<0.01$.

when compared with rabbit corneal endothelial cells, a large number of studies have reported on the method of promoting the proliferation of human corneal endothelial cells in vitro in recent years [45-48]. Our group's ongoing experiments need to be replicated in human corneal endothelial cells to explore the involved mechanisms.

In conclusion, the results of our study demonstrated for the first time that the shear stress of the aqueous humour upregulated the mRNA and protein expression levels of ZO$1, \mathrm{~N}$-cadherin, and $\mathrm{Na}^{+} / \mathrm{K}^{+}$-ATPase in RCECs. This effect suggested that physiological levels of fluid shear stress may contribute to the function of corneal endothelial cells, and this study lays a foundation for further related research in the future.

\section{Data Availability}

The datasets used during the current study are available from the corresponding author upon reasonable request.

\section{Conflicts of Interest}

There are no conflicts of interest.

\section{Authors' Contributions}

SJD conducted most of the experiments in the study. SJD and YJL drafted the manuscript. YYZ, XZ, YM, and DMX analysed the experimental data and edited the figures. GFH 
designed the study and planned the experimental procedures. All the authors have agreed to the published version of the manuscript.

\section{Acknowledgments}

This research was funded by grants from the National Natural Science Foundation of China (No. 81560158 to HGF).

\section{Supplementary Materials}

S1 Figure 1: morphological changes in RCECs after exposure to shear stress were observed under the microscope. (DOCX). (Supplementary Materials)

\section{References}

[1] N. Evans, C. Minelli, C. Minelli et al., "Substrate stiffness affects early differentiation events in embryonic stem cells," European Cells and Materials, vol. 18, no. discussion 13-14, pp. 1-14, 2009.

[2] J. Nam, J. Johnson, J. J. Lannutti, and S. Agarwal, “Modulation of embryonic mesenchymal progenitor cell differentiation via control over pure mechanical modulus in electrospun nanofibers," Acta Biomaterialia, vol. 7, no. 4, pp. 1516-1524, 2011.

[3] L. Chun-Min, W. Hong-Bei, D. Micah, and W. Yu-li, "Cell movement is guided by the rigidity of the substrate," Biophysical Journal, vol. 79, pp. 144-152, 2000.

[4] K. Aditya, K. P. Jesse, and E. J. Adam, "Understanding the extracellular forces that determine cell fate and maintenance," Development (cambridge, England), vol. 144, pp. 4261-4270, 2017.

[5] P. Dan, É. Velot, V. Decot, and P. Menu, "The role of mechanical stimuli in the vascular differentiation of mesenchymal stem cells," Journal of Cell Science, vol. 128, pp. 2415-2422, 2015.

[6] Y. Yao, A. Rabodzey, and C. F. Dewey Jr., "Glycocalyx modulates the motility and proliferative response of vascular endothelium to fluid shear stress," American Journal of Physiology - Heart and Circulatory Physiology, vol. 293, no. 2, pp. H1023-H1030, 2007.

[7] J. Ando and K. Yamamoto, "Vascular mechanobiology endothelial cell responses to fluid shear stress," Circulation Journal, vol. 73, no. 11, pp. 1983-1992, 2009.

[8] C. G. Galbraith, R. Skalak, and S. Chien, "Shear stress induces spatial reorganization of the endothelial cell cytoskeleton," Cell Motility and the Cytoskeleton, vol. 40, no. 4, pp. 317-330, 1998.

[9] K. G. Birukov, A. A. Birukova, S. M. Dudek et al., "Shear stress-mediated cytoskeletal remodeling and cortactin translocation in pulmonary endothelial cells," American Journal of Respiratory Cell and Molecular Biology, vol. 26, no. 4, pp. 453-464, 2002.

[10] H. Xiaobo, S. Naoya, T. Noriko, M. Hui, S. Masaaki, and O. Makoto, "Influence of TGF- $\beta 1$ expression in endothelial cells on smooth muscle cell phenotypes and MMP production under shear stress in a co-culture model," Cytotechnology, vol. 71, no. 2, pp. 489-496, 2019.

[11] A. S. Rodrigo, C. F. Célio Jr., S. F. Geórgia et al., "Laminar shear stress-provoked cytoskeletal changes are mediated by epigenetic reprogramming of TIMP1 in human primary smooth muscle cells," Journal of Cellular Physiology, vol. 234, pp. 6382-6396, 2019.

[12] S. Jinghui, L. Qing, L. Lingling, and S. Guanbin, "Low-level shear stress promotes migration of liver cancer stem cells via the FAK-ERK1/2 signalling pathway," Cancer letters, vol. 427, pp. 1-8, 2018.

[13] L. Anh and T. T. Robert, "Shear conditioning of adipose stem cells for reduced platelet binding to engineered vascular grafts," Tissue engineering Part A, vol. 24, pp. 1242-1250, 2018.

[14] F. Moazzam, F. A. DeLano, B. W. Zweifach, and G. W. Schmid-Schonbein, "The leukocyte response to fluid stress," Proceedings of the National Academy of Sciences, vol. 94, no. 10, pp. 5338-5343, 1997.

[15] S. Fukuda, T. Yasu, D. N. Predescu, and G. W. SchmidSchönbein, "Mechanisms for regulation of fluid shear stress response in circulating leukocytes," Circulation Research, vol. 86, pp. E13-E18, 2000.

[16] A. Ishibazawa, T. Nagaoka, T. Takahashi et al., "Effects of shear stress on the gene expressions of endothelial nitric oxide synthase, endothelin-1, and thrombomodulin in human retinal microvascular endothelial cells," Investigative Opthalmology \& Visual Science, vol. 52, no. 11, pp. 8496-8504, 2011.

[17] U. Hampel, F. Garreis, F. Burgemeister, N. Essel, and F. Paulsen, "Effect of intermittent shear stress on corneal epithelial cells using an in vitro flow culture model," Ocular Surface, vol. 16, no. 3, pp. 341-351, 2018.

[18] B. Molins, A. Mora, S. Romero-Vázquez et al., "Shear stress modulates inner blood retinal barrier phenotype," Experimental Eye Research, vol. 187, Article ID 107751, 2019.

[19] T. Utsunomiya, A. Ishibazawa, T. Nagaoka et al., "Transforming growth factor- $\beta$ signaling cascade induced by mechanical stimulation of fluid shear stress in cultured corneal epithelial cells," Investigative Opthalmology \& Visual Science, vol. 57, no. 14, pp. 6382-6388, 2016.

[20] E. K. Leonard, V. H. Pai, P. Amberg, J. Gardner, and E. J. Orwin, "Design and validation of a corneal bioreactor," Biotechnology and Bioengineering, vol. 109, no. 12, pp. 31893198, 2012.

[21] S. Molladavoodi, M. Robichaud, D. Wulff, and M. Gorbet, "Corneal epithelial cells exposed to shear stress show altered cytoskeleton and migratory behaviour," PLoS one, vol. 12, Article ID e0178981, 2017.

[22] Y. Yamamoto, T. Uno, T. Joko, A. Shiraishi, and Y. Ohashi, "Effect of anterior chamber depth on shear stress exerted on corneal endothelial cells by altered aqueous flow after laser iridotomy," Investigative Opthalmology \& Visual Science, vol. 51, no. 4, pp. 1956-1964, 2010.

[23] Y. Kaji, T. Oshika, T. Usui, and J. Sakakibara, "Effect of shear stress on attachment of corneal endothelial cells in association with corneal endothelial cell loss after laser iridotomy," Cornea, vol. 24, no. 8, pp. S55-S58, 2005.

[24] C. Zhu and N. C. Joyce, "Proliferative response of corneal endothelial cells from young and older donors," Investigative Opthalmology \& Visual Science, vol. 45, no. 6, pp. 1743-1751, 2004.

[25] K. Kosaki, J. Ando, R. Korenaga, T. Kurokawa, and A. Kamiya, "Fluid shear stress increases the production of granulocyte-macrophage colony-stimulating factor by endothelial cells via mRNA stabilization," Circulation Research, vol. 82, no. 7, pp. 794-802, 1998.

[26] N. Joyce, "Proliferative capacity of the corneal endothelium," Progress in Retinal and Eye Research, vol. 22, no. 3, pp. 359-389, 2003. 
[27] D. M. Maurice, "The structure and transparency of the cornea," The Journal of Physiology, vol. 136, no. 2, pp. 263-286, 1957.

[28] S. Dikstein and D. M. Maurice, "The metabolic basis to the fluid pump in the cornea," The Journal of Physiology, vol. 221, no. 1, pp. 29-41, 1972.

[29] W. M. M. Petroll, J. K. W. J. Hsu, J. J. Bean, H. D. D. Cavanagh, and J. V. J. Center, "The spatial organization of apical junctional complex-associated proteins in feline and human corneal endothelium," Current Eye Research, vol. 18, no. 1, pp. 10-19, 1999.

[30] W.-L. Chen, C.-T. Lin, H.-F. Lo, J.-W. Lee, I.-H. Tu, and F.- R. Hu, "The role of protein tyrosine phosphorylation in the cell-cell interactions, junctional permeability and cell cycle control in post-confluent bovine corneal endothelial cells," Experimental Eye Research, vol. 85, no. 2, pp. 259-269, 2007.

[31] J. Fischbarg, F. P. J. Diecke, P. Iserovich, and A. Rubashkin, "The role of the tight junction in paracellular fluid transport across corneal endothelium. Electro-osmosis as a driving force," Journal of Membrane Biology, vol. 210, no. 2, pp. 117-130, 2006.

[32] C. G. Wigham, H. C. Turner, J. Swan, and S. A. Hodson, "Modulation of corneal endothelial hydration control mechanisms by Rolipram," Pfluegers Archiv European Journal of Physiology, vol. 440, no. 6, pp. 866-870, 2000.

[33] C. G. Wigham, J. A. Guggenheim, and S. A. Hodson, "Sodium movement into and out of corneal endothelium," Pflugers Archiv European Journal of Physiology, vol. 428, no. 5-6, pp. 577-582, 1994.

[34] S. Dimmeler, J. Haendeler, V. Rippmann, M. Nehls, and A. M. Zeiher, "Shear stress inhibits apoptosis of human endothelial cells," FEBS Letters, vol. 399, no. 1-2, pp. 71-74, 1996.

[35] E. Sho, M. Sho, T. M. Singh, C. Xu, C. K. Zarins, and H. Masuda, "Blood flow decrease induces apoptosis of endothelial cells in previously dilated arteries resulting from chronic high blood flow," Arteriosclerosis, Thrombosis, and Vascular Biology, vol. 21, no. 7, pp. 1139-1145, 2001.

[36] Y. Zeng, Y. Qiao, Y. Zhang, X. Liu, Y. Wang, and J. Hu, "Effects of fluid shear stress on apoptosis of cultured human umbilical vein endothelial cells induced by LPS," Cell Biology International, vol. 29, no. 11, pp. 932-935, 2005.

[37] M. Morigi, C. Zoja, M. Figliuzzi et al., "Fluid shear stress modulates surface expression of adhesion molecules by endothelial cells," Blood, vol. 85, no. 7, pp. 1696-1703, 1995.

[38] B. S. Conklin, D.-s. Zhong, W. Zhao, P. H. Lin, and C. Chen, "Shear stress regulates occludin and VEGF expression in porcine arterial endothelial cells," Journal of Surgical Research, vol. 102, no. 1, pp. 13-21, 2002.

[39] J. Zhou, Y.-S. Li, and S. Chien, "Shear stress-initiated signaling and its regulation of endothelial function," Arteriosclerosis, Thrombosis, and Vascular Biology, vol. 34, no. 10, pp. 21912198, 2014.

[40] N. E. Ashpole, D. R. Overby, C. R. Ethier, and W. D. Stamer, "Shear stress-triggered nitric oxide release from Schlemm's canal cells," Investigative Ophthalmology \& Visual Science, vol. 55, no. 12, pp. 8067-8076, 2014.

[41] M. Ali, V. Raghunathan, J. Y. Li, C. J. Murphy, and S. M. Thomasy, "Biomechanical relationships between the corneal endothelium and Descemet's membrane," Experimental Eye Research, vol. 152, pp. 57-70, 2016.

[42] N. C. Joyce, "Proliferative capacity of corneal endothelial cells," Experimental Eye Research, vol. 95, no. 1, pp. 16-23, 2012 .
[43] M. Thériault, O. Roy, I. Brunette, and S. Proulx, "Physiological pressure enhances the formation of tight junctions in engineered and native corneal endothelium," Experimental Eye Research, vol. 179, pp. 102-105, 2019.

[44] S. Hodson, "The regulation of corneal hydration to maintain high transparency in fluctuating ambient temperatures," Experimental Eye Research, vol. 20, no. 4, pp. 375-381, 1975.

[45] G. M. Raymond, M. M. Jumblatt, S. P. Bartels, and A. H. Neufeld, "Rabbit corneal endothelial cells in vitro: effects of EGF," Investigative Ophthalmology \& Visual Science, vol. 27, pp. 474-479, 1986.

[46] D. A. Blake, H. Yu, D. L. Young, and D. R. Caldwell, "Matrix stimulates the proliferation of human corneal endothelial cells in culture," Investigative Ophthalmology \& Visual Science, vol. 38, pp. 1119-1129, 1997.

[47] M. Y. Pistsov, E. Y. Sadovnikova, and S. M. Danilov, "Human corneal endothelial cells: isolation, characterization and longterm cultivation," Experimental Eye Research, vol. 47, no. 3, pp. 403-414, 1988.

[48] K. Yamashita, E. Inagaki, S. Hatou et al., "Corneal endothelial regeneration using mesenchymal stem cells derived from human umbilical cord," Stem cells and development, vol. 27, pp. 1097-1108, 2018. 